Bull. Chem. Soc. Ethiop. 2013, 27(2), 161-168.

Printed in Ethiopia

DOI: http://dx.doi.org/10.4314/bcse.v27i2.1

ISSN 1011-3924

(c) 2013 Chemical Society of Ethiopia

\title{
COMBINATION OF FLAME ATOMIC ABSORPTION SPECTROMETRY WITH LIGANDLESS-DISPERSIVE LIQUID-LIQUID MICROEXTRACTION FOR PRECONCENTRATION AND DETERMINATION OF TRACE AMOUNT OF LEAD IN WATER SAMPLES
}

\author{
S.Z. Mohammadi ${ }^{1, *}$, T. Shamspur ${ }^{2}$ and Y.M. Baghelani ${ }^{1}$ \\ ${ }^{1}$ Department of Chemistry, Payame Noor University, Iran \\ ${ }^{2}$ Department of Chemistry, Shahid Bahonar University of Kerman, Kerman, Iran
}

(Received June 1, 2011; revised April 3, 2013)

\begin{abstract}
A new ligandless-dispersive liquid-liquid microextraction method has been developed for the separation and flame atomic absorption spectrometry determination of trace amount of lead(II) ion. In the proposed approach 1,2-dicholorobenzene and ethanol were used as extraction and dispersive solvents. Factors influencing the extraction efficiency of lead, including the extraction and dispersive solvent type and volume, $\mathrm{pH}$ of sample solution, concentration of chloride and extraction time were studied. Under the optimal conditions, the calibration curve was linear in the range of 7.0-6000 $\mathrm{ng} \mathrm{mL}^{-1}$ of lead with $\mathrm{R}^{2}=0.9992(\mathrm{n}=10)$ and detection limit based on three times the standard deviation of the blank $\left(3 \mathrm{~S}_{\mathrm{b}}\right)$ was $0.5 \mathrm{ng} \mathrm{mL}^{-1}$ in original solution. The relative standard deviation for eight replicate determinations of $1.0 \mu \mathrm{g} \mathrm{mL}^{-1}$ lead was $\pm 1.6 \%$. The high efficiency of dispersive liquid-liquid microextraction to carry out the determination of trace amounts of lead in complex matrices was demonstrated. The proposed method has been applied for determination of trace amounts of lead in water samples and satisfactory results were obtained. The accuracy was checked by analyzing a certified reference material from the National Institute of Standard and Technology, Trace elements in water (NIST CRM 1643e).
\end{abstract}

KEY WORDS: Dispersive liquid-liquid microextraction, Lead determination, Preconcentration, Ligandless, Water analysis

\section{INTRODUCTION}

Lead mainly in inorganic form is used in a variety of products, but recently its impact as a major environmental pollutant was recognized. It virtually affects every system in the body. Blood lead levels as low as $100 \mu \mathrm{g} \mathrm{L}^{-1}$ are associated with adverse health effects in children [1]. The World Health Organization (WHO) recommended a limit of $10 \mu \mathrm{g} \mathrm{L}^{-1}$ of lead in drinking water [2], which requires a very sensitive measurement technique.

Currently, the most common analytical methods for lead trace determination are flame atomic absorption spectrometry (FAAS) [3,4], electrothermal atomic absorption spectrometry (ET-AAS) [5], inductively coupled plasma atomic emission spectrometry (ICP-AES) [6] and inductively coupled plasma-mass spectrometry (ICP-MS) [7].

However, aforementioned methods except FAAS involve a greater cost and increased instrumentation complexity; consequently, their widespread application to routine analytical works was limited. FAAS is still being used because it combines a fast analysis time, a relative simplicity and a cheaper cost. Nevertheless, detection of metal trace elements in aqueous samples is difficult due to various factors, particularly their low concentration and the matrix effects [8]. Therefore, to determine trace amounts of $\mathrm{Pb}^{2+}$ ions in aquatic environments by FAAS, a preconcentration technique is usually required.

Recently, Anthemidis and Ioannou [9, 10] successfully applied an on-line sequential injection dispersive liquid-liquid microextraction (DLLME) system to preconcentration of lead. Also, Yousefi and Shemirani [11] developed an ionic liquid-based DLLME method for determination of $\mathrm{Pb}$ ion. Jia and coworkers combined a DLLME with flow injection ICP-MS for

*Corresponding author. E-mail: szmohammadi@yahoo.com 
determination of $\mathrm{Pb}(\mathrm{II})$ ion [12]. Rivas and co-workers developed a DLLME combined with ETAAS for determination of $\mathrm{Pb}$ (II) ion [13]. However, ICP-MS, ICP-OES and ET-AAS involve a greater cost and increased instrumentation complexity; consequently, their widespread application to routine analytical works was limited. Also, on-line sequential injection needs an intelligent interface that may not be available in all laboratories.

Recently we reported a new DLLME method for preconcentration of silver(I) and copper(II) without addition of chelating agent $[14,15]$. In the first work, $\mathrm{Ag}^{+}$ion was extracted at $\mathrm{pH} 5$ and in the second work, $\mathrm{Cu}^{2+}$ ion was extracted at $\mathrm{pH} 10$. According to obtained results, the presence of large amounts of copper had no significant effect on the LL-DLLME of lead (interference-to-analyte ratios $=1000$ ). Although silver was also extracted by this method at $\mathrm{pH}$ 6 , no interference in the determination of lead (interference-to-analyte ratios $=100$ ) was noted. The aim of this work was to combine ligandless-dispersive liquid-liquid microextraction (LLDLLME) with FAAS and developing a new method for determination of trace lead in environmental samples. All main factors were investigated and optimized. The LL-DLLME method was evaluated by analyzing two certified reference material.

\section{EXPERIMENTAL}

\section{Instrumentation}

A SensAA GBC (Dandenong, Australia) atomic absorption spectrometer equipped with deuterium background correction and lead hollow cathode lamp was used for absorbance measurements at wave length of $283.3 \mathrm{~nm}$. The instrumental parameters were adjusted according to the manufacturer's recommendations. The acetylene flow rate and the burner height were adjusted in order to obtain the maximum absorbance signal, while aspirating the analyte solution. A Metrohm $692 \mathrm{pH}$ meter (Herisau, Switzerland) was used for $\mathrm{pH}$ measurements.

\section{Reagents and solutions}

All reagents were of analytical grade and purchased from Merck (Darmstadt, Germany) unless otherwise specified. The laboratory glassware was kept overnight in a $1.4 \mathrm{M} \mathrm{HNO}_{3}$ solution. Before using, the glassware was washed with deionized water and dried. The stock solution of lead at a concentration of $1000 \mu \mathrm{g} \mathrm{mL} \mathrm{m}^{-1}$ was prepared by dissolving appropriate amounts of $\mathrm{Pb}\left(\mathrm{NO}_{3}\right)_{2}$, in $0.2 \mathrm{M}$ of $\mathrm{HNO}_{3}$. The working reference solutions were obtained daily by stepwise dilution from stock solution. A solution of $10 \% \mathrm{NaCl}$ (Merck) was prepared by dissolution of $10 \mathrm{~g}$ of $\mathrm{NaCl}$ in $100 \mathrm{~mL}$ of deionised water. The solutions of alkali metal and various metal salts $(0.1 \% \mathrm{w} / \mathrm{v})$ were used to study the interference of anions and cations, respectively.

\section{LL-DLLME procedure}

All standards and samples were prepared for analysis according to the following procedure. Eight $\mathrm{mL}$ of each sample was placed in a screw cap glass test tube with a conic bottom. To each test tube, $1 \mathrm{~mL}$ of $0.2 \mathrm{M}$ phosphate buffer ( $\mathrm{pH} \mathrm{6)}$ and $1 \mathrm{~mL}$ of $10 \%$ (w/v) $\mathrm{NaCl}$ were added. Then, $2 \mathrm{~mL}$ of ethanol containing $15.0 \mu \mathrm{L}$ of 1,2-dicholorobenzene (1,2-DCB) was rapidly injected into each solution. As a result, cloudy solution (water, ethanol, and 1,2-DCB) was formed in each test tube. In this step, lead reacted with chloride ion and was extracted into the fine droplets of 1,2-DCB. Then, the solution was centrifuged at $4000 \mathrm{rpm}$ for $5 \mathrm{~min}$, and the dispersed fine droplets of 1,2-DCB were deposited at the bottom of conical test tube. The sediment phase was removed by using a micro syringe and sediment phase dissolved in $0.5 \mathrm{~mL}$ of $0.5 \mathrm{M} \mathrm{HNO}_{3}$ in ethanol. The final solution was aspirated directly into the flame of AAS. 


\section{Sample preparation}

For evaluating the accuracy of the proposed method, one certified reference material furnished by the National Institute of Standards and Technology, Trace elements in water (NIST CRM $1643 \mathrm{e}$ ) has been analyzed.

All water samples were collected in acid-leached polyethylene bottles. Kerman tap water and well water samples were collected from our University (Payame Noor University, Kerman, Iran). Mineral water samples were acquired from a local market. The only pretreatment was acidification to $\mathrm{pH} 2$ with nitric acid, which was performed immediately after collection. The samples were filtered before analyses through a $0.45 \mu \mathrm{m}$ pore size cellulose membrane (Millipore).

\section{Extraction mechanism}

At first, phosphate buffer and $\mathrm{NaCl}$ solution were added to lead solution. In this step, lead reacted with chloride ion to form $\mathrm{PbCl}_{2}$, then the aqueous, dispersive and extraction solvents were mixed and a cloudy solution was formed. After formation of cloudy solution, $\mathrm{PbCl}_{2}$ diffuses into the extraction solvent quickly, because of the infinitely large surface area between extraction solvent and the aqueous phase. Then, the solution was centrifuged and the dispersed fine droplets of 1,2-DCB were deposited at the bottom of conical test tube. The sediment phase was removed and $0.5 \mathrm{~mL}$ of $0.5 \mathrm{M} \mathrm{HNO}_{3}$ in ethanol was added to it. The final solution was aspirated directly into the flame of AAS. The extraction scheme of $\mathrm{Pb}$ (II) ion is shown in equation 1.

$$
\begin{aligned}
& \mathrm{Pb}^{2^{+}}+2 \mathrm{Cl}^{-} \rightarrow \mathrm{PbCl}_{2(s)} \\
& \mathrm{PbCl}_{2(s)} \stackrel{1,2-D C B / \text { Ethanol }}{\longrightarrow} \mathrm{PbCl}_{2(1,2-D C B)}
\end{aligned}
$$

\section{RESULTS AND DISCUSSION}

In this study, combination of LL-DLLME with FAAS was developed for determination of trace amounts of lead. It is based on microextraction of lead chloride with ethanol as dispersive solvent and 1,2-DCB as extraction solvent. In order to reach optimum experimental conditions for quantitative extraction of $\mathrm{Pb}$ (II) ions via LL-DLLME, the influence of different parameters such as the extraction and dispersive solvent type and volume, $\mathrm{pH}$ of sample solution, concentration of chloride and extraction time was studied. The recovery percent was calculated through Eq. 2.

$\operatorname{Re} \%=\frac{C_{0} V_{0}}{C_{a q} V_{a q}} \times 100$

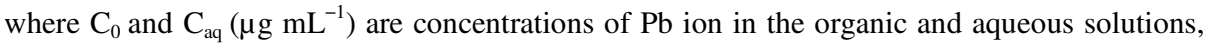
respectively, and $\mathrm{V}_{0}$ and $\mathrm{V}_{\mathrm{aq}}(\mathrm{mL})$ are volumes of organic and aqueous solution, respectively.

Type and volume of disperser solvent

For the DLLME method, the dispersive solvent should be miscible with both water and the extraction solvent. Therefore, acetone, methanol, ethanol and tetrahydrofuran were tested. The 
effect of these solvents on the extraction efficiency of LL-DLLME of lead was investigated using $2.0 \mathrm{~mL}$ of each solvent containing $15.0 \mu \mathrm{L}$ of $1,2-\mathrm{DCB}$ as the extraction solvent. The extraction efficiency of LL-DLLME for lead in acetone, methanol, ethanol and tetrahydrofuran as disperser solvents were $78.1,92.4,98.7$ and 88.9 , respectively. Due to its lower toxicity as compared to methanol, ethanol was chosen as the disperser solvent for subsequent studies.

Also, the volume of the dispersive solvent is one of the important factors in DLLME. For investigating the effect of disperser solvent volume on extraction efficiency, various volumes of ethanol (0.5-3 mL) containing $15 \mu \mathrm{L} \mathrm{1,2-DCB}$ were used. The results showed that the extraction efficiency increased with increasing volume of ethanol to $1.5 \mathrm{~mL}$ and remained constant to 2.5 $\mathrm{mL}$. Reduction in the extraction efficiency was observed after the volume of ethanol exceeded $2.5 \mathrm{~mL}$. At low volumes, ethanol could not disperse 1,2-DCB properly and cloudy solution was not formed completely. Reversely, at high volumes, the solubility of analyte in water increased. Therefore, $2 \mathrm{~mL}$ ethanol was chosen as the optimum volume.

\section{Type and volume of extraction solvent}

The selection of an appropriate extraction solvent was very critical for DLLME process. The most important point in the course of selecting extraction solvent for DLLME was that the extraction solvent must have higher density than water. Based on these facts, variety of water immiscible organic solvents, such as dichloromethane $\left(\mathrm{CH}_{2} \mathrm{Cl}_{2}\right)$, chloroform $\left(\mathrm{CHCl}_{3}\right)$, carbon tetrachloride $\left(\mathrm{CCl}_{4}\right)$ and 1,2-dichlorobenzene (1,2-DCB) were investigated as the possible extraction solvents for LL-DLLME. The results showed that, after the addition of $\mathrm{CH}_{2} \mathrm{Cl}_{2}$ and $\mathrm{CHCl}_{3}$ not only the cloudy state was formed but also no sedimentation phase on the bottom of the test tube noted after centrifugation. It was due to higher solubility of these solvents in water than the other tested solvents.

For this purpose, 1,2-dicholorobenzene (1,2-DCB) and carbon tetrachloride $\left(\mathrm{CCl}_{4}\right)$ were studied as extraction solvents. The effect of these solvents on the extraction efficiency of lead was investigated using $2.0 \mathrm{~mL}$ of ethanol containing $15 \mu \mathrm{L}$ of each solvent. The extraction efficiencies of LL-DLLME for lead in 1,2-DCB and $\mathrm{CCl}_{4}$ as extraction solvent were 98.7 and 88.9 , respectively. Therefore, 1,2-DCB was selected as extraction solvent for subsequent experiments.

Also, in order to examine the effect of the extraction solvent volume, solutions containing different volumes of 1,2-DCB $(15-100 \mu \mathrm{L})$ were subjected to the same LL-DLLME procedure. It was observed that the extraction efficiency was constant up to $30 \mu \mathrm{L}$ and then, by increasing the volume of 1,2-DCB from 30 to $100 \mu \mathrm{L}$, the extraction efficiency decreased probably due to the decrease in the ratio between the dispersive solvent and the extraction solvent. By decreasing this ratio, the number of droplets available for extraction and the extraction efficiency decreased. Based on these observations, a volume of $15 \mu \mathrm{L}$ was used for further experiments.

\section{Effect of $p H$}

The effect of $\mathrm{pH}$ of sample solution on the LL-DLLME of lead was studied in the range of 3 to 8.5, while keeping the other variable constant. The results are shown in Figure 1 and revealed that the recovery was nearly constant in the $\mathrm{pH}$ range of 5.7-6.5. Therefore, $\mathrm{pH} 6$ was selected for further studies. In $\mathrm{pHs}$ lower than $5.7, \mathrm{PbCl}_{2}$ could not completely be formed and extracted into extraction solvent. In pHs higher than $6.5, \mathrm{~Pb}(\mathrm{OH})_{2}$ could compete with $\mathrm{PbCl}_{2}$, which might prevent complete transfer into extraction solvent. 


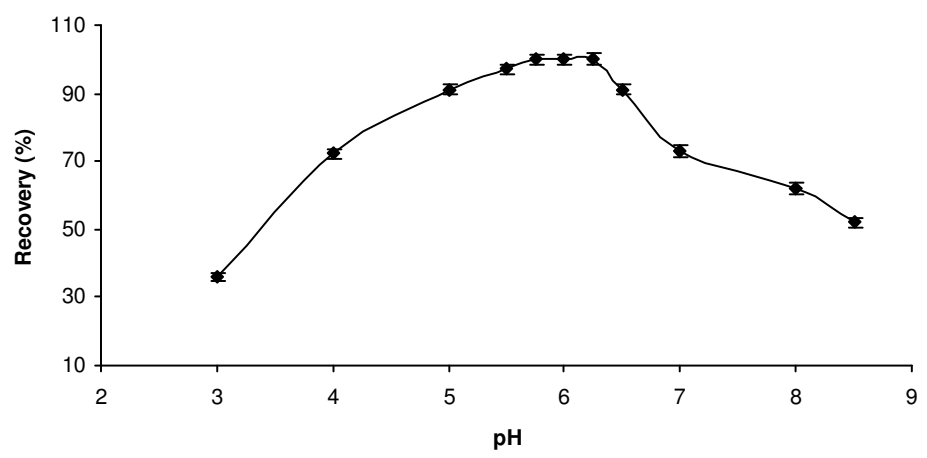

Figure 1. Effect of $\mathrm{pH}$ of the sample solution on the LL-DLLME extraction of lead. Conditions: $\mathrm{Pb}(\mathrm{II}), 10.0 \mu \mathrm{g}$; ethanol, $2 \mathrm{~mL}$; $\mathrm{NaCl} 10 \%$ (w/v), $1 \mathrm{~mL}$ and 1,2-DCB, $15.0 \mu \mathrm{L}$.

\section{Effect of chloride concentration}

In the case of many microextraction procedures, $\mathrm{Pb}$ (II) ions should firstly form hydrophobic complex in the aqueous solution in order to be extracted into organic phase [14-15]. In this research, lead reacted with chloride ion for $\mathrm{PbCl}_{2}$ formation, which then diffused into the extraction solvent quickly. Therefore, effect of chloride concentration on the LL-DLLME of lead should be studied. For this purpose, several experiments were performed by adding different amounts of $\mathrm{NaCl}$ ranging from 0.025 to $0.15 \mathrm{~g}$, while keeping the other variable constant. The results showed that the extraction efficiency increased with increasing $\mathrm{NaCl}$ up to $0.1 \mathrm{~g}$. Any amount in excess of $0.1 \mathrm{~g} \mathrm{NaCl}$ showed no effect on the extraction efficiency. Therefore, $1 \mathrm{~mL}$ of $10 \%(\mathrm{w} / \mathrm{v}) \mathrm{NaCl}$ was used in all further experiments.

\section{Effect of extraction time}

The extraction time was studied according to previous reports $[14,15]$. The obtained results showed that the extraction time had no significant influence on the extraction. In this method, the most time-consuming step was the centrifuging of sample solution in the extraction procedure. The process took about $5 \mathrm{~min}$.

\section{Effect of foreign ions}

To perform this study, diverse ions in different interference-to-analyte ratios were added to a solution containing $10.0 \mu \mathrm{g}$ of $\mathrm{Pb}(\mathrm{II})$ and were subjected to the recommended procedure. Table 1 shows the tolerance limits of the interference ions (error $\pm 5 \%$ ). The results demonstrate that the presence of large amounts of species commonly present in water samples have no significant effect on the LL-DLLME of lead.

\section{Calibration, precision and detection limit}

Repeatability, linearity, correlation coefficient and detection limit were investigated under the optimized experimental conditions. For a sample volume of $8.0 \mathrm{~mL}$, the calibration curve exhibited linearity over the range of $7.0 \mathrm{ng} \mathrm{mL}^{-1}-6.0 \mu \mathrm{g} \mathrm{mL}^{-1}$ with a correlation coefficient of $0.9995(\mathrm{~A}=0.1646 \mathrm{C}+0.0012)$. Eight replicate determinations of $1.0 \mu \mathrm{g} \mathrm{mL} \mathrm{L}^{-1}$ lead gave a mean absorbance of 0.165 with relative standard deviation of $\pm 1.6 \%$. The detection limit was $0.5 \mathrm{ng}$ 
$\mathrm{mL}^{-1}$. Enrichment factor was calculated as the ratio of the slope of calibration curve after and before microextraction step. The enrichment factor for lead was 15.5.

Table 1. Tolerance limit of foreign ions.

\begin{tabular}{|c|c|c|c|}
\hline Foreign ions & Added as & Interference/ $\mathrm{Pb}$ (II) ratio & Recovery (\%) \\
\hline $\mathrm{PO}_{4}^{3-}$ & $\mathrm{Na}_{3} \mathrm{PO}_{4} \cdot 12 \mathrm{H}_{2} \mathrm{O}$ & 5000 & 96 \\
\hline $\mathrm{H}_{2} \mathrm{PO}_{4}^{-}$ & $\mathrm{K}_{2} \mathrm{HPO}_{4} \cdot 6 \mathrm{H}_{2} \mathrm{O}$ & 5000 & 96 \\
\hline $\mathrm{HPO}_{4}{ }^{2-}$ & $\mathrm{Na}_{2} \mathrm{HPO}_{4} \cdot 12 \mathrm{H}_{2} \mathrm{O}$ & 5000 & 96 \\
\hline $\mathrm{CH}_{3} \mathrm{COO}^{-}$ & $\mathrm{CH}_{3} \mathrm{COONa}$ & 1000 & 95 \\
\hline $\mathrm{Na}^{+}$ & $\mathrm{NaCl}$ & 4000 & 104 \\
\hline $\mathrm{K}^{+}$ & $\mathrm{KNO}_{3}$ & 4000 & 104 \\
\hline $\mathrm{Ca}^{2+}$ & $\mathrm{CaCl}_{2}$ & 2000 & 105 \\
\hline $\mathrm{Mg}^{2+}$ & $\mathrm{Mg}\left(\mathrm{NO}_{3}\right)_{2}$ & 2000 & 105 \\
\hline $\mathrm{Co}^{2+}$ & $\mathrm{Co}\left(\mathrm{NO}_{3}\right)_{2} \cdot 6 \mathrm{H}_{2} \mathrm{O}$ & 1000 & 95 \\
\hline $\mathrm{Cu}^{2+}$ & $\mathrm{Cu}\left(\mathrm{NO}_{3}\right)_{2} \cdot 3 \mathrm{H}_{2} \mathrm{O}$ & 1000 & 95 \\
\hline $\mathrm{Mn}^{2+}$ & $\mathrm{MnSO}_{4} \cdot \mathrm{H}_{2} \mathrm{O}$ & 1000 & 95 \\
\hline $\mathrm{Zn}^{2+}$ & $\mathrm{ZnCl}_{2}$ & 1000 & 95 \\
\hline $\mathrm{Fe}^{2+}$ & $\mathrm{FeCl}_{2}$ & 200 & 95 \\
\hline $\mathrm{Fe}^{3+}$ & $\mathrm{FeCl}_{3}$ & 200 & 95 \\
\hline $\mathrm{Ni}^{2+}$ & $\mathrm{Ni}\left(\mathrm{NO}_{3}\right)_{2} \cdot 6 \mathrm{H}_{2} \mathrm{O}$ & 800 & 105 \\
\hline $\mathrm{Al}^{3+}$ & $\mathrm{Al}\left(\mathrm{NO}_{3}\right)_{3} \cdot 9 \mathrm{H}_{2} \mathrm{O}$ & 50 & 96 \\
\hline $\mathrm{Cr}^{3+}$ & $\mathrm{Cr}\left(\mathrm{NO}_{3}\right)_{3} \cdot 9 \mathrm{H}_{2} \mathrm{O}$ & 600 & 95 \\
\hline $\mathrm{Sn}^{2+}$ & $\mathrm{SnCl}_{2}$ & 700 & 105 \\
\hline $\mathrm{Sb}^{3+}$ & $\mathrm{SbCl}_{3}$ & 500 & 96 \\
\hline $\mathrm{Cd}^{2+}$ & $\mathrm{CdCl}_{2}$ & 500 & 96 \\
\hline $\mathrm{Ag}^{+}$ & $\mathrm{AgNO}_{3}$ & 100 & 95 \\
\hline
\end{tabular}

Conditions were the same as in Figure 1.

Accuracy of the method

For evaluating the accuracy of the proposed method, one certified reference material furnished by the National Institute of Standard and Technology, Trace elements in water (NIST CRM $1643 \mathrm{e}$ ) has been analyzed. An aliquot of the certified reference material was taken and lead ion was determined by the LL-DLLME procedure. It was found that there is no significant difference at the $95 \%$ confidence level between results obtained by the LL-DLLME procedure $\left(19.81 \pm 0.8 \mathrm{ng} \mathrm{mL}^{-1}\right)$ and the certified value $\left(19.63 \pm 0.21 \mathrm{ng} \mathrm{mL}^{-1}\right)$.

\section{Analysis of real samples}

The proposed procedure has been applied to the determination of lead content in tap water, well water and two different mineral water samples. The results are given in Table 2 . The recovery of lead from water samples spiked with $\mathrm{Pb}$ (II) samples was also studied. The results are given in Table 2. According to this Table, the added lead ion can be quantitatively recovered from the water samples by the proposed procedure. These results demonstrate the applicability of the procedure for lead determination in water samples. The recovery of lead added to the samples demonstrates the efficiency of the proposed method.

\section{Comparison of LL-DLLME procedure with the other reported methods}

A comparison of the current method with the other reported methods [16-19] is shown in Table 3. The results showed that, the enrichment factor and the detection limit obtained by the proposed method are comparable to methods reported in the literature. 
Table 2. Determination of lead in water sample.

\begin{tabular}{|l|c|c|c|}
\hline \multirow{2}{*}{ Sample } & \multicolumn{2}{|c|}{ Lead amount $\left(\mathrm{ng} \mathrm{mL}^{-1}\right)$} & \multirow{2}{*}{ Recovery $(\%)$} \\
\cline { 2 - 4 } & Added & Found & ---- \\
Tap water & 0.0 & $7.8 \pm 0.3$ & 102 \\
\hline Well water & 30.0 & $38.4 \pm 1.6$ & ---- \\
& 0.0 & BLR & 104 \\
\hline Mineral water 1 & 30.0 & $31.2 \pm 1.3$ & ---- \\
& 0.0 & BLR $^{*}$ & 108 \\
\hline Mineral water 2 & 30.0 & $32.4 \pm 1.4$ & ---- \\
& 0.0 & $7.4 \pm 0.3$ & 99.3 \\
\hline
\end{tabular}

*Below linear range.

Table 3. Comparison of the reported methods with the proposed method.

\begin{tabular}{|c|c|c|c|c|c|}
\hline $\begin{array}{c}\text { Enrichment } \\
\text { method }\end{array}$ & $\begin{array}{c}\text { Detection } \\
\text { method }\end{array}$ & $\begin{array}{c}\text { Enrichment } \\
\text { factor }\end{array}$ & $\begin{array}{c}\text { Sample } \\
\text { volume }(\mathrm{mL})\end{array}$ & $\begin{array}{c}\text { Detection limit } \\
\left(\mathrm{ng} \mathrm{mL}^{-1}\right)\end{array}$ & Reference \\
\hline CPE & FAAS & 15.1 & 15 & 4.5 & 16 \\
\hline DLLME & FAAS & 450 & 25 & 0.5 & 17 \\
\hline Coprecipitation & FAAS & 125 & 50 & 16 & 18 \\
\hline LLE & FAAS & 543 & 500 & 0.39 & 19 \\
\hline CPE & FAAS & 50 & 10 & 8.0 & 20 \\
\hline LL-DLLME & FAAS & 15.5 & 8 & 0.5 & This work \\
\hline
\end{tabular}

\section{CONCLUSIONS}

It has been demonstrated that LL-DLLME combined with flame atomic absorption spectrometry provides a novel route for trace determination of lead in natural waters. The main benefits of the LL-DLLME methodology are minimum use of toxic organic solvents $(15.0 \mu \mathrm{L}$ of 1,2dicholorobenzene), simplicity, low cost, enhancement of sensitivity, and rapid analysis time (maximum $10 \mathrm{~min}$ ).

\section{REFERENCES}

1. Dadfarnia, S.; Salmanzadeh, A.M.; Haji Shabani, A.M. Anal. Chim. Acta 2008, 623, 163.

2. Baird, C. Environmental Chemistry, 2th ed., W.H. Freeman Company: New York; 1999; p 95.

3. dos Santos, W.L.; dos Santos, C.M.M.; Costa, J.L.O.; Andrade, H.M.C.; Ferreira, S.L.C. Microchem. J. 2004, 77, 123.

4. Zachariadis, G.A.; Anthemidis, A.N.; Bettas, P.G.; Stratis, J.A. Talanta 2002, 57, 919.

5. Cabon, J.Y. Spectrochim. Acta Part B 2002, 57, 513.

6. Koksal, J.; Synek, V.; Janos, P. Talanta 2002, 58, 325.

7. Ndungu, K.; Hibdon, S.; Flegal, A.R. Talanta 2004, 64, 258.

8. Chena, J.; Xiao, S.; Wu, X.; Fang, K.; Liu, W. Talanta 2005, 67, 992.

9. Anthemidis, A.N.; Ioannou, K.I.G. Anal. Chim. Acta 2010, 668, 35.

10. Anthemidis, A.N.; Ioannou, K.I.G. Talanta 2009, 79, 86.

11. Yousefi, S.R.; Shemirani, F. Anal. Chim. Acta 2010, 669, 25.

12. Jia, X.; Han, Y.; Liu, X.; Duan, T.; Chen, H. Microchim. Acta 2010, 171, 49.

13. Rivas, R.E.; Lopes Garcia, L.; Hernandez Cordoba, M. Microchim. Acta 2009, 166, 355.

14. Mohammadi, S.Z.; Afzali,. D.; Taher, M.A.; Baghelani, Y.M. Talanta 2009, 80, 875. 
15. Mohammadi,. S.Z.; Afzali,. D.; Baghelani, Y.M. Anal. Chim. Acta 2009, 653, 173.

16. Silva, E.L.; Roldan, P.D.S. J. Hazard. Mater. 2009, 161, 142.

17. Naseri, M.T.; Hemmatkhah, P.; Milani Hosseini, M.R.; Assadi, Y. Anal. Chim. Acta 2008, $610,135$.

18. Doner, G.; Ege, A. Anal. Chim. Acta 2005, 547, 14.

19. Carasek, E.; Tonjes, J.W.; Scharf, M. Talanta 2002, 56, 185.

20. Tavallali, H.; Asrari, E.; Attaran, A.M.; Tabandeh, M. Int. J. ChemTech Res. 2010, 2, 1731. 